\title{
Biodegradation of Petroleum Hydrocarbon Using Pseudomonas and Its Antifungal Activity Against Phytopathogens
}

\author{
T. Rajeswari ${ }^{a}$, B. Elayarajah ${ }^{\mathrm{b}}$, B. Venkatrajah', S. Rajakumar ${ }^{\mathrm{d}}$, \\ S. Meenatchisundaram ${ }^{\mathrm{e} *}$ and R. Vijayaraghavan ${ }^{\mathrm{e}}$ \\ ${ }^{a}$ Department of Microbiology, Karpagam University, Coimbatore - 641021, ${ }^{b}$ Department of Microbiology, CMS \\ College of Science and Commerce, Coimbatore - 641006, ' ${ }^{c}$ Department of Bioinformatics, CMS College of \\ Science and Commerce, Coimbatore - 641 006, ${ }^{d}$ Department of Environmental Management, Bharadhidasan \\ University, Trichy, ${ }^{e}$ Department of Microbiology, Nehru Arts and Science College, \\ Coimbatore - 641105, Tamil Nadu, India.
}

\begin{abstract}
Fluorescent Pseudomonas isolated from oil-spilled soil was studied for the degradation of oil (Commercially available castor 2T oil) sample by growing in Bushnell Hass medium. The hydrocarbon degradation was measured colorimetrically in the basal media based on the turbidity. The degraded oil sample was utilized for studying its efficiency in Phaseolus aureus seeds germination. The thin layer chromatographic technique differentiates the specific components of antifungal metabolites and was isolated by centrifugation technique showed the $\mathrm{Rf}$ value of about 0.34 . Antagonistic potential of these metabolites were demonstrated by agar diffusion method and spot inoculation method. The present study thus demonstrated the ability of the isolated Pseudomanas fluorescens to utilize crude oil in liquid media and to compete with indigenous soil microorganisms, enhance crude oil degradation and reduces its phytotoxicity.
\end{abstract}

Key words: Biodegradation, Petroleum hydrocarbons, Pseudomanas fluorescens, Phytopathogen, Antifungal activity.

\section{Introduction}

Biodegradation is a natural processes by which microbe alters of break down petroleum hydrocarbons into other substances (Bragg et al., 1994). The rate of degradation depends upon the concentration of microbes and upon the environmental characteristics of an oil contaminated ecosystem (EPA, 1990 ). Bacteria that consume petroleum are known as "Hydrocarbon oxidizers" because they oxidize compounds to bring about degradation (Atlas, R.M., 1977 and 1981). Among the degrading bacteria Pseudomonas species have been found to be the most versatile (Chakrabarthy, 1972). Biodegradation process alone reduces crude oil spills. Fungi are a major phytopathogen for plants, causing various diseases such as wilt, mildews, rust, tikka, blight. Instead of using chemical fungicides, metabolites producing organisms can be used as anti fungal agents (Rovera et al., 2000). Pseudomonas species that can colonize the roots of crop plants and produce antifungal metabolites represent a real alternative to the application of chemical fungicides (Ultan et al., 2001).

* Corresponding author: E-mail: drmscbe@gmail.com

\section{Materials and Methods}

Isolation and Identification of Pseudomonas sp.

Soil sample from oil spilled region liberated from oil refinery industry outlet was collected. The sample was serially diluted and spread plated on nutrient agar plate and incubated at $37^{\circ} \mathrm{C}$ for $24-48$ hours. The isolated colonies were streaked on King's B medium containing (g/L) Glycerine10 , Protease peptone- $20, \mathrm{MgSO}_{4}-1.5, \mathrm{pH}-7$ and incubated at $35^{\circ} \mathrm{C}$ for $24-48$ hours. Similarly King's B broth was prepared and the sample was inoculated and incubated at $37^{\circ} \mathrm{C}$ for 24-48 hours. The pigment producing colonies were selected and Gram staining and biochemical reactions were performed (Villegas et al., 2002).

\section{Crude oil biodegradation in shake flask experiment}

Degradation of crude oil during growth of Pseudomonas in shake flask experiments was carried out by inoculating $1 \mathrm{ml}$ stationary phase culture into $50 \mathrm{ml}$ Bushnell Hass Medium containing $(\mathrm{g} / \mathrm{L}) \mathrm{KH}_{2} \mathrm{PO}_{4-} 1, \mathrm{~K}_{2} \mathrm{HPO}_{4-}$ 1, $\mathrm{NH}_{4} \mathrm{NO}_{3-}$, 
$\mathrm{MgSO}_{4} \cdot 7 \mathrm{H}_{2} \mathrm{O}-0.2, \mathrm{FeCl}_{3-} 0.05, \mathrm{CaCl}_{2} \cdot 2 \mathrm{H}_{2} \mathrm{O}-0.02$, pH- 7 (Bushnell and Hass, 1941) with $0.5 \%$ of crude oil contained in $250 \mathrm{ml}$ Erlenmeyer flasks and incubated on a rotatory shaker $\left(180 \mathrm{rpm}, 28^{\circ} \pm 2^{\circ} \mathrm{C}\right)$ for the required time. Uninoculated flasks containing medium and crude oil served as controls during the incubation period. Residual crude oil with bacterial suspension was extracted and the turbidity was measured colorimetrically at $420 \mathrm{~nm}$.

\section{Effect of bioaugmentation of Pseudomonas fluorescens on plant growth in oil contaminated soil}

To determine the efficacy of Pseudomonas fluorescens treated oil to support seed germination and plant growth, $150 \mathrm{~g}$ unsterile garden soil was dispensed in plastic pots $(7 \mathrm{~cm} \mathrm{X}$ $6 \mathrm{~cm} \times 6 \mathrm{~cm}$ ) and bioaugmented with Pseudomonas fluorescens. 10 mung beans (Phaseolus aureus) were then planted per pot at a depth of $1 \mathrm{~cm}$, and the results in terms of number of seeds germinated; length of stem and leaves of the plants were noted for 5 to 10 days. The following controls were used: soil with Pseudomonas fluorescens treated oil, soil with undegraded crude oil and soil with water (Hanson et al., 1997).

Extraction, purification and chemical identification of antifungal metabolites from degraded oil compounds

\section{Extraction of antifungal metabolites from degraded oil compounds}

The degraded oil compounds extracted from the Bushnell Hass broth was inoculated into King's B media and incubated for 24-48 hours. Following incubation, the broth was centrifuged at $8000 \mathrm{rpm}$ for 20 minutes. The supernatant obtained was collected and equal amount of $70 \%$ acetone was added and again centrifuged at $8000 \mathrm{rpm}$ for 20 minutes. The supernatant was taken and equal amount of diethyl ether was added and centrifuged at $8000 \mathrm{rpm}$ for 20 minutes. The resulting supernatant containing antifungal metabolites were collected and stored at $4^{\circ} \mathrm{C}$ (Rovera et al., 2000).

\section{Partial purification of antifungal metabolite}

The collected antifungal extracts were treated with saturated ammonium sulphate solution ( $\mathrm{pH} 7.4)$. The precipitate was centrifuged at $11,000 \mathrm{rpm}$ for 20 minutes. The pellet was redissolved in $0.2-0.5 \mathrm{ml}$ of buffers without $\mathrm{NaCl}$. The pooled fraction was transferred to active dialysis bag. The contents were pooled into the dialysis bag and tied after including some air and twisting the open end of the dialysis bag. The bag containing pooled contents were dispensed into buffer $\mathrm{S}$ (with out $\mathrm{NaCl}$ ) for dialysis process. The contents were dispensed into eppendoff tubes and centrifuged in order to remove the remaining impurities. Once the dialysis was over, the fractions were used for further analysis like thin layer chromatography and antagonistic activity (Rovera et al., 2000).

\section{Chemical identification using thin layer chromatograph- ic technique}

Silica gel slurry was prepared with double distilled water in the ratio of $2: 1$. It was then applied over the glass plates at thickness of $0.25 \mathrm{~mm}$ with the help of TLC applicator. The plates were kept in the oven at $100-120^{\circ} \mathrm{C}$ for $1-2$ hours to remove moisture content and also to activate the adsorbent. $25 \mu 1$ of sample and standard amino acids were applied as small spots. The plates were dried and placed the plate vertically in the chromatography chamber already saturated with solvent vapor, containing developing solvent to a depth of $1.5 \mathrm{~cm}$. Once the solvent had reached the top, the plate was removed and proceeded for identification of spotted compound using $0.3 \%$ of ninhydrin solution. It was then kept in oven at $100^{\circ} \mathrm{C}$ for $2-3$ minutes observed for coloured spots and the $\mathrm{R}_{\mathrm{f}}$ value was calculated (Rovera et al., 2000).

\section{Antagonistic effect on fungal pathogens}

Fungal pathogens such as Fusarium sp., Aspergillus sp, Penicillium sp were isolated in Potato Dextrose Agar (PDA) media. They were then subcultured and inoculated into Czapek dox broth and incubated for one week. Antagonistic effect on fungal pathogen was done by Agar diffusion method and Spot inoculation method (Modified Shanahan et al., 1992).

\section{Agar Diffusion method}

Fungal spore suspension from each of the fungal broth was swabbed over the PDA agar plates. Small wells were made on the centre of the plate using a well borer. About $50 \mu$ l of purified antifungal extract was added to the wells with the help of a micropipette and measured the zone of inhibition around the wells (Manwar, et al., 2000).

\section{Spot inoculation method}

PDA media was prepared and $10 \mathrm{ml}$ of antifungal extract was added before the solidification of the media. The fungal cul- 
tures were spot inoculated on to agar medium. Antifungal compounds treated with $50 \mu 1$ ferric chloride were kept as control because it nullifies the action of the antifungal metabolites. The plates were kept for incubation at room temperature for 1 week (Weger, et al., 1986).

\section{Results and Discussion}

\section{Isolation and identification of the genus Pseudomonas sp}

Oil spilled soil samples were collected from various oilspilled sites and all the samples were analyzed for isolation of oil degrading Pseudomonas sp. Spread plating technique was performed for initial screening of the organism. The Table I shows the number of colonies grown from the collected soil samples. Gram-staining technique reveals that the screened colonies belong to pink colored short slender rod-

Table I: Bacterial strain isolation from oil spilled soil by spread plate technique

\begin{tabular}{l|c|c}
\hline S. No & Dilution number & Number of colonies \\
\hline 1 & $10^{-2}$ & TNTC \\
2 & $10^{-3}$ & TNTC \\
3 & $10^{-4}$ & 56 \\
4 & $10^{-5}$ & 19 \\
5 & $10^{-6}$ & 14 \\
6 & $10^{-7}$ & 8 \\
\hline
\end{tabular}

Table II: Gram-staining technique to identify the type of the bacterium

\begin{tabular}{l|c}
\hline Staining protocols & Identification \\
\hline Gram's staining & Gram negative \\
Shape of the bacterium & Short rods \\
\hline
\end{tabular}

Table III. Biochemical tests of the isolates

\begin{tabular}{l|c|c}
\hline S.No. & Biochemical test & Result \\
\hline 1. & Oxidase test & Positive \\
2. & Indole test & Negative \\
3. & Methyl red & Negative \\
4. & Voges-proskauer & Negative \\
5. & Catalase test & Positive \\
6. & Citrate utilization test & Positive \\
7. & Triple sugar iron agar test & AK/AK \\
\hline
\end{tabular}

shaped organisms (Table II). The biochemical properties of the screened out colonies were tabulated in Table III. The antimicrobial activity of Pseudomonas fluorescens were shown in Table IV.

Table IV: Antibiotic Sensitivity for Pseudomonas fluorescens

\begin{tabular}{l|c|c}
\hline S. No. & $\begin{array}{c}\text { Antibiotics } \\
\text { Conc } 10 \mu / \mathrm{ml})\end{array}$ & $\begin{array}{c}\text { Resistance } \\
\text { of the microbe }\end{array}$ \\
\hline 1 & Penicillin $\mathrm{G}$ & Resistant \\
2 & Novobiocin & Sensitive \\
3 & Lincomycin & Resistant \\
4 & Ofloxacin & Sensitive \\
\hline
\end{tabular}

\section{Biodegradation of hydrocarbon using the soil isolated Pseudomonas sp.,}

Oil samples with different concentration was added to the BHB and incubated for 4 to 7 days. Optical density of both oil and degraded oil in BHB were recorded colorimetrically at $420 \mathrm{~nm}$ (fig 1 and fig 2). Enumeration of petroleumdegrading microorganisms is important both to determine the potential for removal of oil via microbial degradation and to assess the amount of oil pollution that has occurred. Petroleum-degrading microorganisms were isolated from samples of sea water and bottom sediments. Several methods were used to enumerate the petroleum-degrading bacteria including the most probable number (MPN) method, plating on oil agar, basal media and silica gel oil agar media. Their results suggested that silica gel oil medium is recommended for enumeration of petroleum-degrading bacteria (Walker and Colwell, 1976). Mills et al. (1978) compared several media designed for use in an MPN determination of petroleum-degrading microorganisms. The best results, i.e, largest numbers were obtained with $32 \mathrm{mM}$ phosphate buffered liquid media containing $1 \%$ hydrocarbon substrate. In this study, turbidity was used as the criterion for establishing positive results.

With reference of this, in the present study, the hydrocarbon degradation was measured colorimetrically, in the basal media-Bushnell Hass broth based on the turbidity. Increased turbidity in the oil degraded basal media documents that hydrocarbon acts as sole carbon source, which degrades hydrocarbon in the natural environment. 


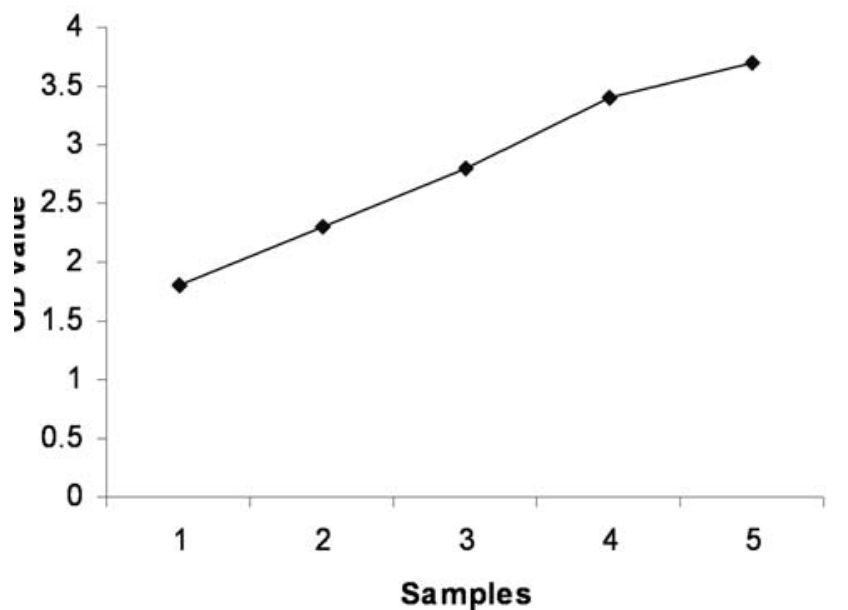

Fig.1. Colorimetric value of oil supplemented in the BHB (420nm)

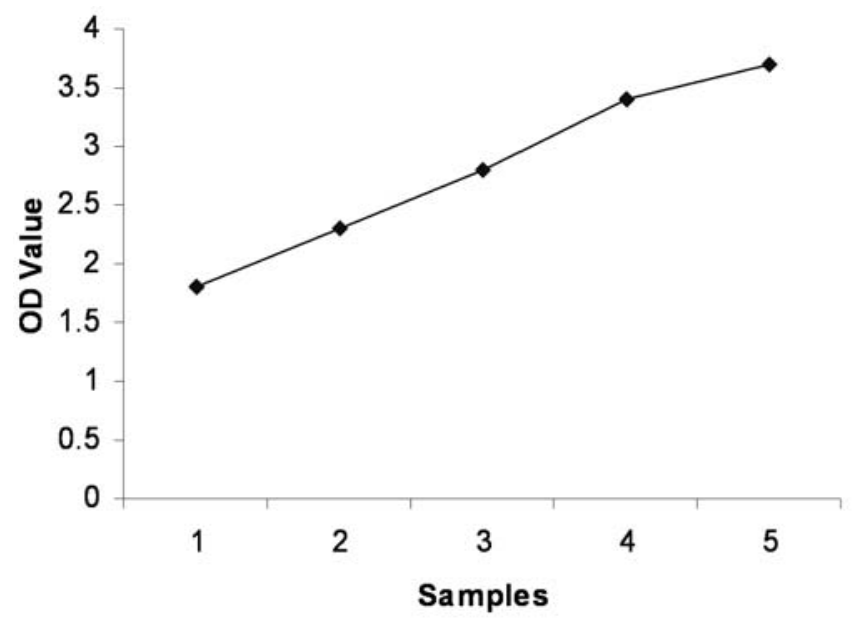

Fig. 2. Colorimetric value of degraded oil with culture in BHB (420nm)

Fig 1 and 2 - Oil samples with different concentration was added to the BHB and incubated for 4 to 7 days. Optical density of both oil and degraded oil in BHB were recorded colorimetrically at $420 \mathrm{~nm}$

\section{Bioremediation}

Biodegradation of the hydrocarbon may yields many intermediate components which may be even more harmful to the environment when compared to the former. So bioremediation of the degraded oil content was recommended. It can be implemented by checking the efficiency of the degraded oil for seed germination and the production of antifungal compounds in the degraded oil and broth culture.
Bioremediation potential of degraded oil by checking seedling germination

Good viable seeds of Phaseolus aureus were selected for the pot culture technique and were sown in the soil .Watered with distilled water, degraded oil sample and with commercially available castor $2 \mathrm{~T}$ oil separately. Good growth of the shoot and leaves were observed in the sterile distilled water germinated seeds. Similarly the germinated seeds with degraded oil sample also showed good growth when compared with the oil-germinated seeds (Fig 3 and Fig 4).

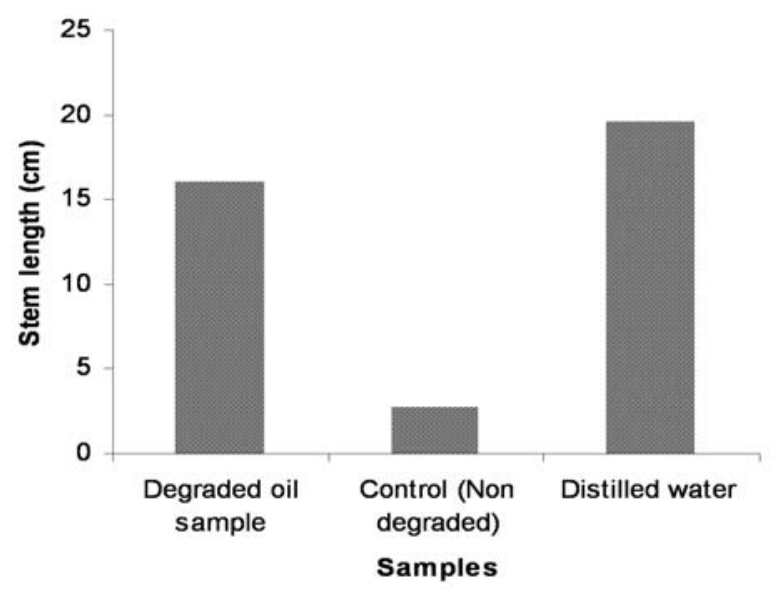

Fig. 3: Propagation of Germinated Phaseolus aureus seeds through pot culture for stem length determination

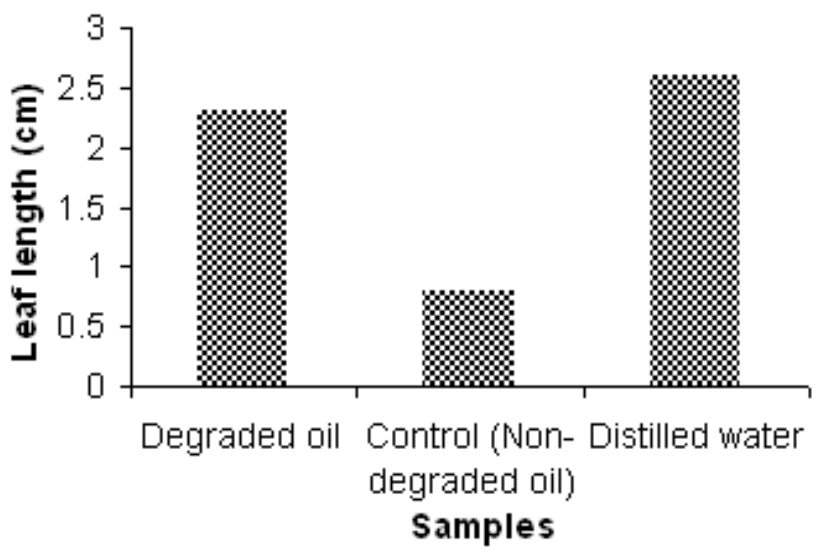

Figure. 4. Propagation of germinated Phaseolus aureus seeds thorough pot culture for leaf length determination

Fig 3 and 4 - Good growth of the shoot and leaves were observed in the sterile distilled water germinated seeds. Similarly the germinated seeds with degraded oil sample also showed good growth when compared with the oil-germinated seeds. 


\section{Extraction and chemical identification of antifungal compounds from the degraded oil content}

The antifungal metabolites extracted by modified protocol of Rovera et al., (2000) from the degraded oil content were subjected to thin layer chromatographic analysis reveals two different spots. The samples were applied as small spots $(25 \mu \mathrm{l})$ along with standard amino acid samples and $\mathrm{R}_{\mathrm{f}}$ value for separated components were calculated. $R_{f}$ values, 0.34 and 0.6 obtained, in which $R_{\mathrm{f}} 0.34$ shows antagonistic activity against fungal plant pathogens.

\section{Antagonistic activity of extracted metabolites}

Antifungal metabolites extracted (Rovera et al., 2000) from fluorescent pseudomonads were prepared in different concentration and analysed for its antagonistic activity against phytopathogens, Fusarium sp., Aspergillus sp., and Penicillium sp., by two different techniques, agar diffusion and spot inoculation methods (Manwar et al., 2000) and (Weger et al., 1986). The zone of inhibition around the well was measured and demonstrated and tabulated (Fig. 5).

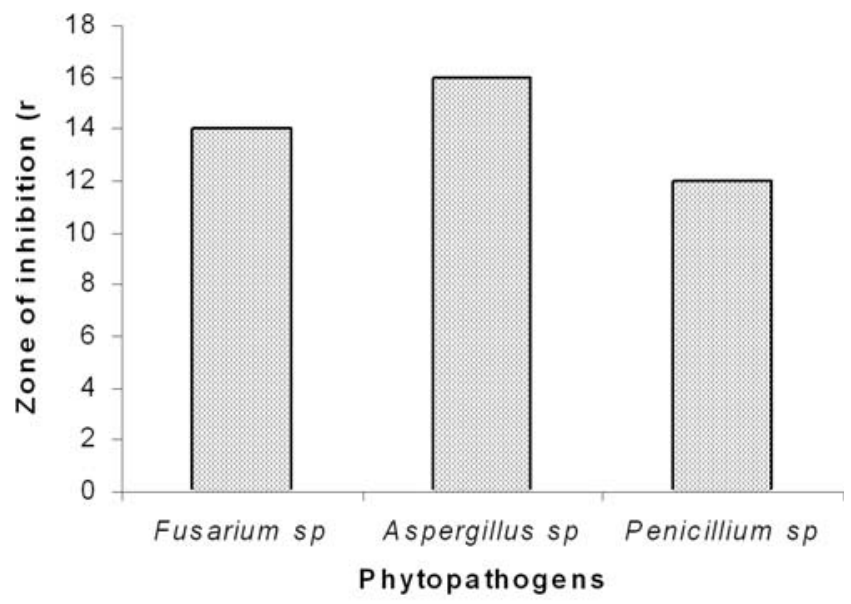

Fig. 5: Antifungal activities of extracted metabolites by agar diffusion method

Fig 5 - Antagonistic potential of these metabolites were demonstrated as a bioremediative study by using two methods like agar diffusion method and spot inoculation method. In both methods, the growths of phytopathogens like Fusarium sp., Aspergillus sp., and Penicillium sp. were suppressed.

The cell extract from the broth with degraded oil was centrifuged to obtain antifungal metabolites. The metabolites were separated by partial purification methods such as ammonium sulphate precipitation and dialysis. Finally, the components were identified by using thin layer chromatography and observed as fluorescent spots under UV light. This spot was scrapped off from the plate and the isolated compounds were then undergone bioassay by using phytopathogenic fungi. The antifungal metabolites isolated by using centrifugation technique show the $R_{f}$ value of about 0.34. According to Bonsall et al. (1997), the siderophore samples with an $R_{f}$ value 0.35 is of the type pyocin which act as an antifungal metabolite. Hence, the isolated antifungal metabolite may belong to the type of siderophores, antagonistic potential of these metabolites were demonstrated as a bioremediative study by using two methods like agar diffusion method and spot inoculation method (Manwar et al., 2000 and Weger et al., 1986). In both methods, the growths of phytopathogens like Fusarium sp., Aspergillus sp., and Penicillium sp. were suppressed. The zone of inhibition around the well containing metabolites indicates the antagonistic potential properties.

\section{Conclusion}

Pseudomonas sp. was isolated from oil spilled soil samples. Shake flask experiment was carried out to check the degradation efficiency of petroleum hydrocarbons by inoculating the isolated Pseudomonas sp, in to Bushnell Hass medium containing crude oil. Increased turbidity in the oil degraded basal media reveals that hydrocarbon present in the crude oil acts as sole carbon source for Pseudomonas sp. Degraded oil sample was subjected to bioremediation by checking the efficiency of the degraded oil for seed germination. Good growth of the shoot and leaves were observed with degraded oil sample when compared with the crude oil sample. Partial purification of the degraded oil sample was done by ammonium sulphate precipitation and dialysis. To identify the antifungal metabolites, the samples were subjected to thin layer chromatography. $\mathrm{R}_{\mathrm{f}}$ values, 0.34 and 0.6 were obtained, in which $R_{f} 0.34$ shows antagonistic activity against fungal plant pathogens. Antagonistic potential of these metabolites were demonstrated as a bioremediative study by using two methods like agar diffusion method and spot inoculation method. In both methods, the growths of phytopathogens like Fusarium sp., Aspergillus sp., and Penicillium sp. were suppressed by showing zone of inhibition. 


\section{References}

Atlas R. M. (1981). Microbial degradation of petroleum hydrocarbons; an environmental perspective. Microbiol. Rev. 45: 180-209.

Atlas R. M. (1977). Stimulated petroleum biodegradation. Critical reviews in Microbiology. 5: 371-386.

Bonsall R. F., Weller D. M. and Thomashow L. S. (1997). Quantification of 2, 4 diacetyl phloroglucinol by Pseudomonas aurantiaca for its use as bio control inoculant. $E M B O J .8: 162$.

Bragg J. R., Prince R. C., Harner E. J. and Atlas R. M. (1994). Effectiveness of bioremediation for Exxon Valdez oil spill. Nature. 368: 413 -418.

Bushnell L. D. and Hass H. F. (1941). The utilization of certain hydrocarbons by microorganisnms. $J$. Bacteriol. 41: 653 - 673.

Chakrabraty A. M. (1972). Genetic basis of the biodegradation of salicylate in Pseudomonas 112(2): 815-823.

EPA, Office of Research and Development. Alaskan Oil Spill Bioremediation Project. 1990 July 20p. Available from: U.S. Government Printing Office. Washington DC: EPA/600/8-89/073.

Hanson K. G. Anuranjini N., Madhavi K., Anjana and Desai J. (1997). Bioremediation of crude oil contamination with Acinetobacter sp A3. Current Microbiology. 35: $191-193$.

Manwar A. V., Khandelwal S. R., Chaudhari B. L., Meyer J. M. and Chincholkar S. B. (2003). Siderophore production by a marine Pseudomonas aeruginosa and its antagonistic action against phytopathogenic fungi. Applied Biochemistry and Biotechnology. 118: 243251.
Mills A. L., Breuil C. and Colwel R. R. (1978). Enumeration of petroleum degrading marine and estuarine microorganisms by the most probable number method. Can. $J$ Microbiol. 24: 552-557.

Rovera M. S., Cabrera N. Correa and Rosas S. (2000). Characterisation of antifungal agents produced by Psedomanas sp. Applied Environmental Microbiology. 56 : 908 - 912.

Shanahan P, Sullivan D. J. O. Simpson P. Glennon, J. D. and F.O' Gara. (1992). Isolation of 2, 4 diacetyl phloro glucinol from a fluorescent Pseudomonad and investigation of physiological parameters influencing its production. Appl. Environ. Microbiol. 58: 353-358.

Ultan F., Walsh J. P., Morrissey and F.O'Gara. (2001). Pseudomonas for biocontrol of phytopathogens from functional genomics to commercial exploitation. Current opinion in Biotechnology. 12: 289-295.

Villegas M. E. D. Pilar Vila. Alina frias. (2002). Evaluation of the siderophores production by pseudomonas aeruginosa PSS. Microbiologia. 44:112-117.

Walker J. D. and Colwell R. R. (1976). Enumeration of petroleum degrading Microorganisms. Appl. Environ. Microbio. 31: 198-207.

Weger L. A., van Boxtel R., van der burg B., Gruters R. A., Geels F. P., Schippers B. and Lugtenberg L. (1986). Siderophores and outer membrane proteins of antagonistic, plant-growth stimulating, root-colonizing Pseudomonas spp. J.Bacteriology. 165: 585-594.

Received : December 06, 2009;

Accepted : January 03, 2011 